\title{
INNERGY
}

\section{Jorge Baradit}

"Salvador Altamirano", decía el parte del día.

El agente se aferró al papel empuñándolo como para golpear a alguien, quizá a su trabajo, a su vida completa o al administrativo que, estaba seguro, había sonreído burlonamente cuando le designó la tarea.

Los velociclos de polea son incómodos, pero los tranvías de catapulta mecánica son aún peores. La inercia entre impulsos te puede quebrar el cuello si no estás mirando en la dirección correcta cuando se enciende la luz de aviso y llega la patada.

A lo lejos, comenzaba a recortarse el segundo pabellón de la "Penitenciaría de alta seguridad ciudadana".

Las famosas penitenciarías estaban dispuestas en anillo en torno a la ciudad, siempre junto a las instalaciones de los generadores "Montoya". Estos generadores no eran más que enormes galpones donde miles de caballos corrían día y noche sobre cintas transportadoras, moviendo dínamos ineficientes y generadores desenterrados de entre las ruinas de ciudades argentinas. Cientos de galpones dispuestos simétricamente rodeaban la capital con su bramido espantoso, solo comparable al de un enorme deslizamiento de tierra o la rotura de una represa monstruosa. Santiago dormía junto al sonido del desastre.

El agente recordó de pronto que ese mismo día, veinte de diciembre, se cumplían doce años desde los últimos bombardeos. Pero la gente parecía haber olvidado todo: el colapso del sistema energético, las invasiones de hordas de citadinos a los pueblos más autónomos del sur, la ley marcial y el desarrollo desesperado de nuevas fuentes de energía. La locura parecía haberse desatado en todos lados y las autoridades desesperadas echaban mano de todo cuanto pudiera asegurarles, al menos, esperanza. Santiago se había vuelto una ciudad en penumbras, cruzada por cables de alta tensión muertos, como las venas de un cadáver descompuesto. La ciudad hedía y el cielo, ennegrecido por la quema de todo cuanto pudiera quemarse, parecía la sombra de algún mal recuerdo que no quiere retirarse. Si bien ya nadie mataba por un litro de gasolina, todavía una buena batería de auto podía desatar un enfrentamiento entre delincuentes y traficantes. El Estado había requisado todas las pilas voltaicas, baterías de automóvil y hasta las pequeñas baterías domésticas con las que se hacían funcionar linternas y radios. Si el Comando Conjunto (la policía interministerial de la energía) supiera que aún guardo un juguete de mi hijo con las baterías puestas podría ser dado de baja y enviado a la cárcel. De hecho, al desgraciado que tengo que visitar lo mandaron preso por razones similares, aunque de muy distinta envergadura. 
Salvador Altamirano está preso con una condena de cuarenta años por atentar contra un punto de acopio de dínamos de bicicleta. Y él estaba ahí para investigar las razones de una acción a todas luces demente. Desde el derrumbe del Medio Oriente y la escalada de violencia que siguió al descalabro de los equilibrios energéticos, todos sabían que la energía se había convertido en una propiedad valiosa de la comunidad que había que defender con la vida.

Todos recuerdan dónde estaban cuando el presidente insistió en que la energía eléctrica era la sangre de un país, y que en esos instantes nuestro territorio se estaba desangrando. Llamó a todo buen hijo de esta tierra a colaborar activamente en la convalecencia de la patria. Anunció los nuevos impuestos al uso de energía, la necesidad de que cada ciudadano pagara sus tributos en volts a través de la generación doméstica de electricidad. Indicó que la educación estaría orientada a la generación de pequeños volúmenes de energía por parte de algo tremendamente valioso que había que explotar: la inquietud infantil. Los pupitres tendrían pedales, los recreos serían orientados a actividades en aparatos mecánicos generadores pintados de colores. Les recordó la necesidad de que cada ciudadano se involucrara en los planes de desarrollo de nuevas fuentes de energía. Insistió en el reclutamiento de voluntarios para las últimas investigaciones en torno a la energía liberada por la ira y los orgasmos, y la posibilidad de producir cámaras acumuladoras viables, apoyadas por los experimentos con jaurías de perros en anfetaminas encerrados en estanques aislados. Recordó la heroica y extenuante labor de búsqueda que realizaban los "raiders" en las ruinas de las ciudades devastadas. La necesidad de nuevos reclutas que escarbaran entre los restos de la civilización en busca de pilas, dínamos, acumuladores y reactivos químicos. Recordó compungido la tragedia de Viña del Mar, donde veinte jóvenes murieron mientras buceaban en la ciudad sumergida buscando un generador de hospital. Llamó al sacrificio, llamó al compromiso. Lloró de angustia frente al país reunido en la plaza de la Constitución, frente a las ruinas del palacio de La Moneda. Todo el país lloró con él, las radios a cuerda se convirtieron en el único nexo en un territorio largo y accidentado, desde la frontera con Perú en Antofagasta, hasta la frontera con las colonias israelíes en Aysén.

Fue como una guerra, siempre hay pérdidas en las guerras. Me miro las manos y no veo nada, miro hacia fuera y siento que nadie en el mundo entero siente el vacío que tengo donde debería estar mi corazón. Quizá hay espacio para dos baterías en mi interior, las baterías del juguete que me espera en casa.

La esperanza regresó cuando el gobierno anunció la puesta en marcha de tres proyectos: los generadores "Montoya", el proyecto "Desierto Florido" y las unidades de emergencia "Pudahuel". Quienes viajan al norte pueden ver enormes dínamos a cuerda alineados en 
campos que se pierden en el horizonte. Seis yuntas de bueyes tiran de sogas metálicas, contrayendo la espiral de cobre monstruosa que esconde cada edificio con forma de catedral. El ruido que hacen se pierde en la vastedad del paisaje. Si quedaran aviones operativos, podrías ver la forma de una estrella hecha con pequeños puntos negros desde las alturas. El proyecto "Desierto Florido" es la gran esperanza de los ingenieros del Ministerio de Energía. Y si algún día el nuevo sistema interconectado de bueyes, caballos, seres humanos y generadores solares fallara, aún quedarían las unidades de emergencia "Pudahuel", enormes edificios de concreto sin ventanas, construidos en las afueras de la capital, que esconden descomunales pistones del tamaño de una torre de treinta pisos. Activados con explosivos, mueven un cigüeñal gigantesco escondido bajo tierra a través de la capital. Miles de personas se mueven dentro y fuera de los edificios entre el vapor y los gritos, apoyados por el Ejército y unidades de zapadores expertos que activan las cargas sincronizados por señales de banderas.

Pero nada es tan perfecto, a pesar de los maravillosos esfuerzos de las autoridades, un año atrás habían comenzado una serie de atentados contra la energía que activaron cambios drásticos en la legislación vigente: a partir de entonces los delitos producirían penas calculables en voltios. Y las más graves entre ellas eran, por supuesto, las penas por delitos contra la energía. Rápidamente se habilitaron los cordones penitenciarios y sus oscuras "cámaras de ratones", recintos subterráneos enormes donde los prisioneros eran puestos a correr en ruedas de acero de grandes dimensiones, similares a las ruedas de hamsters. Los reos debían producir una cantidad de kilovatios diarios que se restaban de la pena asignada a su delito. Y mi entrevistado, Salvador Altamirano, estaba condenado a producir una cantidad de kilovatios tal, que estaría corriendo en los galpones durante por lo menos cuarenta años, si corría duro y sin cejar.

Cuando ingreso al recinto me invade la angustia. El hacinamiento es espantoso, el hedor es insoportable. Los presos duermen de pie colgados de cuerdas a las vigas del techo, de esa manera es fácil "cortar" a los más débiles o los moribundos y dejarlos caer sobre las carretillas que los llevaran a los patios. Reviso mi dínamo personal, una pieza de lujo que se mueve con mis pisadas y me permite acumular el tributo semanal sin mayores problemas, y opto por guardarlo en un bolsillo más seguro, el lugar no parece nada de confiable y los guardias son los que más desconfianza me producen.

-Vengo a ver al preso 655321, Salvador Altamirano.

El guardia ni siquiera me mira.

-Soy oficial del Ministerio de Energía, sargento.

Entonces gira la cabeza lentamente y veo que está comiendo un trozo de manzana, quién sabe el favor que hizo para tener acceso a semejante joya. Obviamente, la exhibe como muestra de su influencia. 
-Lo está esperando en la salita de reuniones -agrega con suavidad aparente-. Le aconsejo que la haga corta, él sabe perfectamente que cada minuto que pasa es un minuto más lejos de su libertad, señor secretario.

-No soy secretario, soy un agente de inteligencia del Ministerio -le digo, algo ofuscado. -Ok, lo que usted quiera. La salita está por allá.

El lugar está en penumbras, aunque en lo más alto de las paredes una hilera de ventanillas da la impresión de ser una línea de focos de iluminación. Pero es una estupidez, yo mismo no veo focos encendidos desde hace meses. Giro por el primer pasillo que me lleva directo a una pequeña puerta grasosa y oxidada.

-Lo estoy esperando hace tres minutos.

-Discúlpame si no me importa, necesito hacerte unas preguntas y nada más. No creas que vine porque me interesa este resort.

-Entonces hágalas y terminemos, tengo cuotas que cumplir.

-Es sencillo, eres el primero de ustedes, quienes quiera que sean, capturado vivo y queremos saber qué mierda te impulsó a hacer semejante estupidez, así de simple.

-Tú no sabes nada de lo que hacemos...

-iExacto! ¿Empezamos?

-Si acepté hablar es porque de esa manera quizá la gente abra los ojos y conozca la verdad de...

-¡La verdad!..., espérame, deja sacar mi pistola..., brrr..., la verdad.

-iVoy a poder hablar sin ser interrumpido?

-Ok, disculpa..., no he tenido buenos encuentros con "la verdad" últimamente.

-Hace años que fuimos instruidos acerca de la verdad, y solo ahora llegó el momento de darla a conocer. Nuestro guía nos...

-Espérate un poco, ¿"Nuestro guía"? ¿Me quieres decir que toda esta tontera es producto de una secta o algo así?

-No somos una secta, somos guerreros de una resistencia metafísica.

$-\ldots$

$-\ldots$

$-\ldots$

- ¿Me estai hueveando, cierto...?

-Vas a ser el primero en saber la verdad fuera de nuestro círculo.

-Me siento honradísimo...

-Estamos llamados a liberar el espíritu humano.

- ¿Rompiendo dínamos de bicicleta?

- ¡Los dínamos no son lo importante! La energía es lo importante. La energía no es lo que tú crees.

-Ok, ¿entonces...?

-¿Por qué crees que la civilización se está cayendo a pedazos? 
-Me muero por escuchar el por qué.

-Fue la señal que indica el comienzo de la batalla por la liberación del espíritu, el fin del samsara y la esclavitud de la materia.

-Pero..., iy los dínamos?

- ¿Es que no entiendes? La electricidad no es lo que tú crees, la electricidad es energía viva. Por los cables de cobre circulan espíritus humanos en profundo dolor y pena, esclavizados por mecanismos abominables que los usan como sangre y alma para moverse. Seres de metal y plástico que se mueven animados por electricidad, que es espíritu humano canalizado. Y Dios dijo: "intentará construir una figura semejante a él, pero fracasará al hacerla vivir y será arrojado al lago de fuego por dos mil años".

-A ver, espérate un poco...

-En el siglo XIX, magos y alquimistas consiguieron construir los conjuros y vías para capturar y conducir los espíritus que rondan libres por la naturaleza, para animar sus maquinarias e insuflarles vida. Durante siglos animaron sus golems despreciables con espíritu humano que corre por los conductores inflamado, quemándose, consumiéndose entre horribles padecimientos. Si solo pudiéramos acercar nuestros oídos a los cables que cruzan nuestra ciudad y oír sus aullidos de dolor.

-Pero tú estai más loco que una cabra...

-Nuestra labor es sagrada. Matar la ciudad y sus arterias de cobre que esclavizan a los seres de luz que realmente somos. Liberar toda la energía atrapada en pilas y baterías como quien abre la jaula a niños hermosos que quieren salir a respirar. Desatar la entropía generalizada y liquidar este universo-cárcel que nos tiene amarrados a este cuerpo-bolsa-maloliente, lejos de la presencia divina de la luz eterna.

-Ok..., entendí..., eres un terrorista.

-No, soy un bodhisattva...

-Ok, un fanático religioso..., terrorista.

-Un guerrero de la luz.

-Ya sabía que iba a ser un día de mierda.

Me quedó claro que no iba a sacarle nada más a este imbécil, así que me puse de pie mientras él seguía vociferando frases altisonantes y muy confusas, al menos para mí. La puerta se cerró y caminé de regreso a la realidad.

-Día de mierda...

Afuera, el día había mejorado en algo, al menos pude distinguir el disco solar entre tanta bruma negruzca. Confieso que miré de manera diferente los cables de alta tensión que cruzaban la ciudad. No demoré más de dos horas en sacarme esas tonteras de la cabeza, pero al llegar al minúsculo departamento que me entregaba el ministerio, lo primero que hice fue sacar el juguete de Martín. Luego de mirarlo durante varios minutos, encendí el interruptor y lo dejé encendido, bailoteando frente a mis ojos hasta que las lucecitas comenzaron a atenuarse poco a poco. Lo miré extinguirse, apagarse como una vela, como un recuerdo doloroso que se aleja..., lo dejé ir. Nunca olvidaré a Martín, pero tengo que dejarlo ir o me volveré loco. 
Después, solo me quedé ahí, muerto, sin energía, vacío de algo que no podría describir con claridad. Quizá de cordura. Todos estamos enloqueciendo rápidamente.

Meneé la cabeza y miré por la ventana.

Santiago parecía una ciudad muerta también. Pronto no quedará nadie que recuerde cómo se veía completamente iluminada, chispeante y engalanada como un cielo de estrellas derramándose sobre la tierra. 